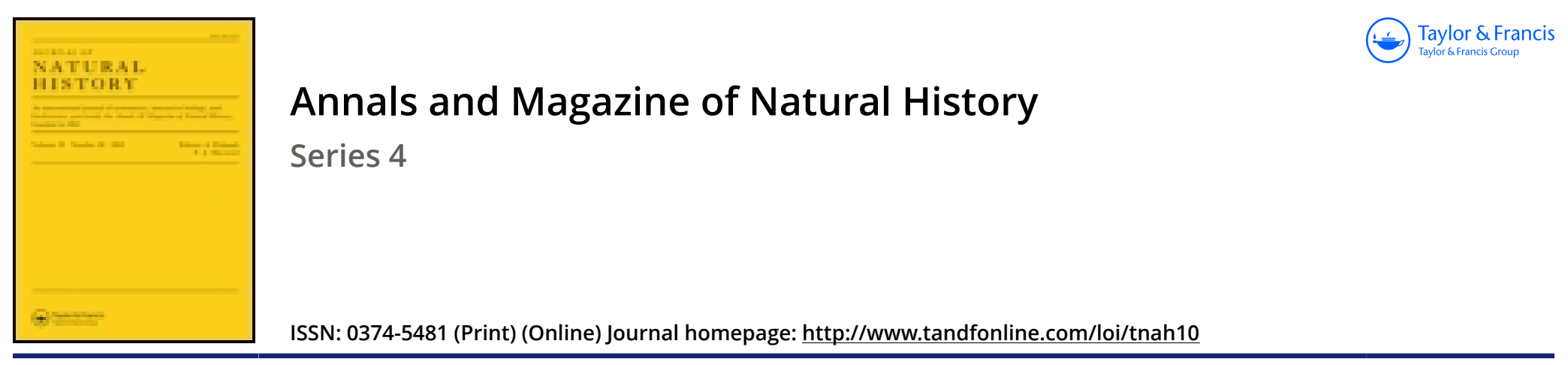

\title{
XV.-Description of Bdelloidina aggregata, a new genus and species of Arenaceous Foraminifera, in which their so-called "Imperforation" is questioned
}

\section{H.J. Carter F.R.S.}

To cite this article: H.J. Carter F.R.S. (1877) XV.-Description of Bdelloidina aggregata, a new genus and species of Arenaceous Foraminifera, in which their so-called "Imperforation" is questioned, Annals and Magazine of Natural History, 19:111, 201-209, DOI: $10.1080 / 00222937708682123$

To link to this article: http://dx.doi.org/10.1080/00222937708682123

曲 Published online: 13 Oct 2009.

Submit your article to this journal

Ш Article views: 3

View related articles $\sqsubset$ 


\title{
THE ANNALS
}

AND

\section{MAGAZINE OF NATURAL HISTORY.}

\author{
[FOURTH SERIES.]
}

No. 111. MARCH 1877.

XV.-Description of Bdelloidina aggregata, a new Genus and Species of Arenaceous Foraminifera, in which their so-called "Imperforation" is questioned. By H.J.CARTER, F.R.S.\&c.

[Plate XIII. figs. 1-8.]

Bdelloidina aggregata, n. gen. et sp. (PI. XIII. figs. 1-8.)

Arenaceous, sessile, flat, composed of linear chambers snccessively applied to each other longitudinally on the same plane, more or less curved simply or tortuously ; following the irregularities of the surface on which the species may be growing (Pl. XIII. fig. 1). Composition calcareous. Colour grey. Surface uniformly consisting of rounded grains of calcareous sand of various sizes below 5-1800ths inch in diameter, together with fragments of siliceous sponge-spicules set pearl-like in a minutely granular calcareous material, which thus serves as a cement to the larger portions (fig. 3). Furrowed by lincs or grooves that indicate the form and extent of the chambers respectively (fig. $1, b$ ), which vary much both in size and shape; tending irregularly though generally to a spiral, planiform aggregation. Presenting on the convexity or outer side of the last-formed chamber a series of circular foramina about 5-1800ths inch in diameter and 10-1800ths inch apart, arranged more or less regularly in a line from one end to the other (fig. 1, a, and fig. 5, a). Chamber constructed on all sides of calcareous sand, \&c., similar to that of the surface (fig. 6); more or less interrupted Ann.\& Mag. N. Hist. Ser. 4. Vol. xix. 

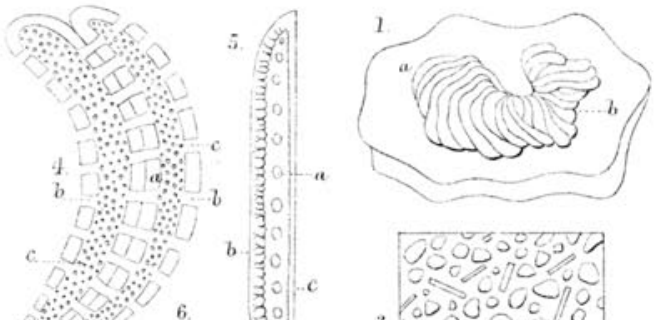

$a \frac{v_{c}^{M t_{f}}}{c} b$
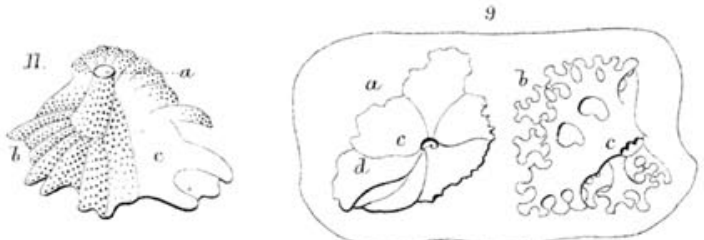
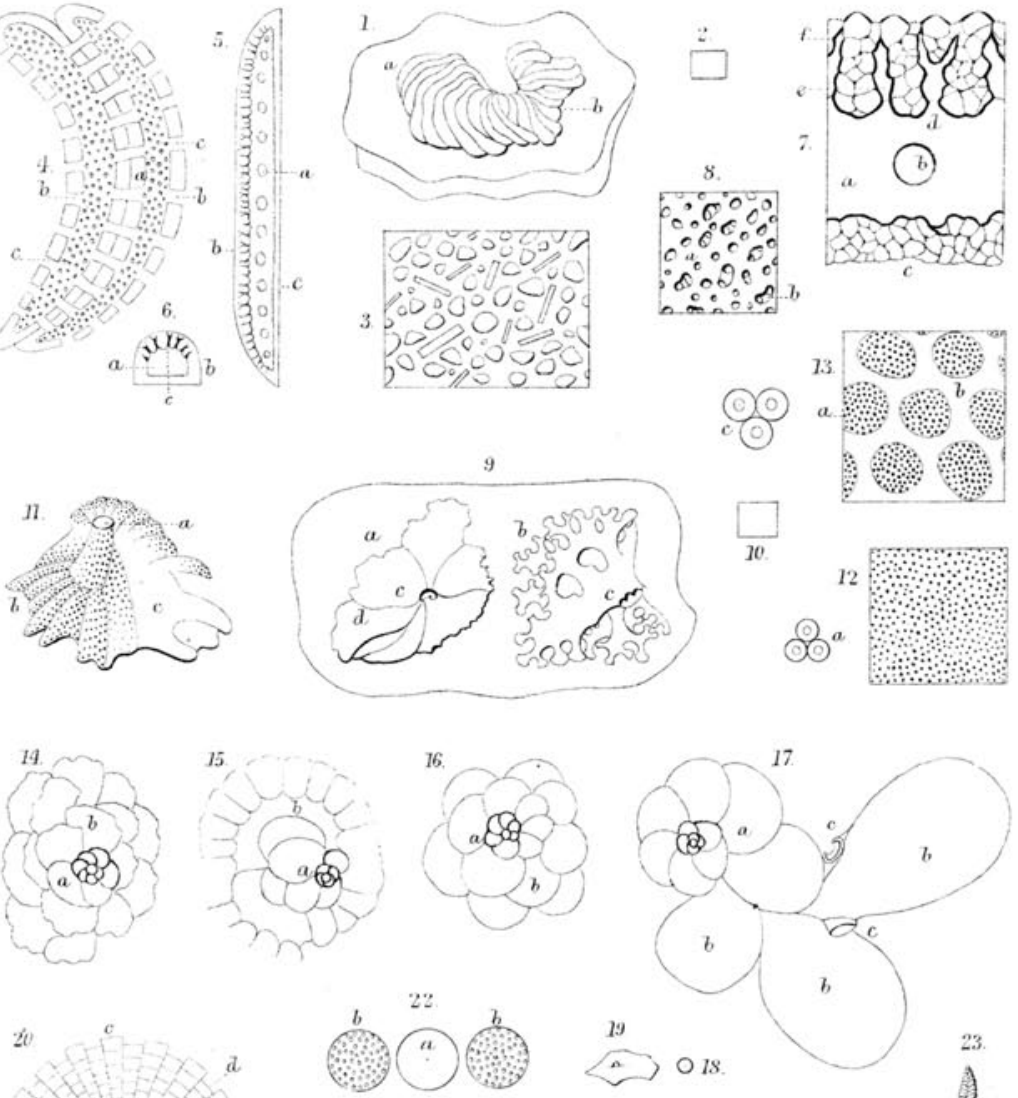

23.<smiles>[C]1[CH]C=C1</smiles>
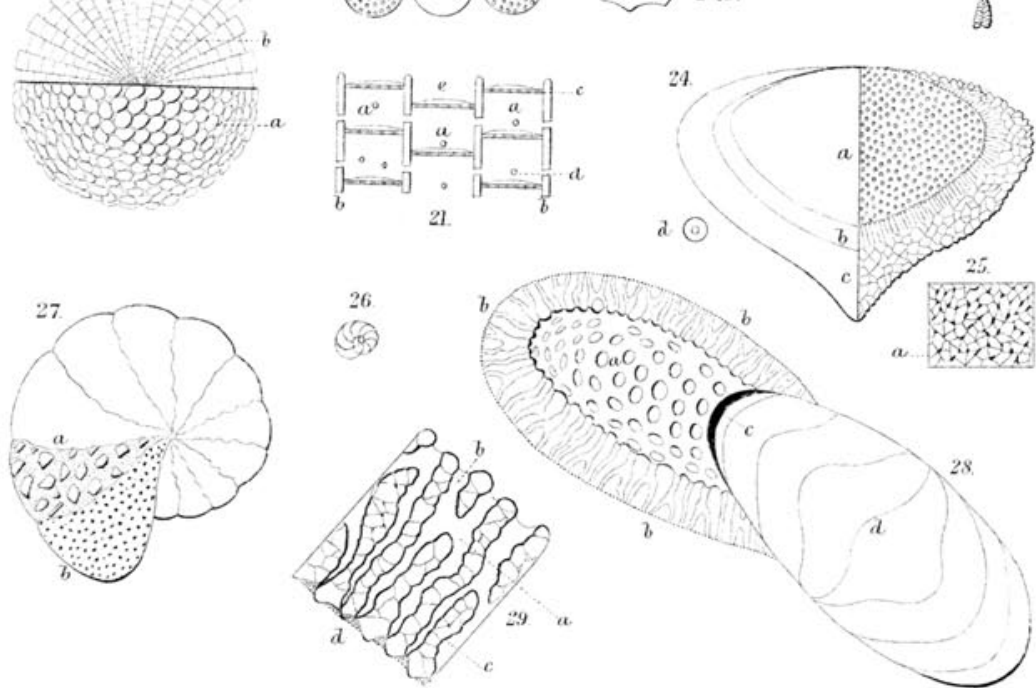

a Buis 
in its cavity transversely by reticulated rugæ of the same material, which, in prominent relief, hanging down from the roof, produce an extremely irregular surface, owing to the large grains of sand of which the ruga are composed, but the whole rendered smooth by sarcodic lining throughout; presenting a row of large apertures on each side, about the same size as, and arranged in a similar manner to those on the convexity of the exterior of the last-formed chamber (fig. $4, b b$ ), which, as the latter is successively added, become the septal holes of intercameral communication (fig. 5, a); also presenting a great number of smaller holes varying in diameter below 2-1800ths inch, situated respectively in the deep interstices of the reticulated rugæ hanging from the roof (fig. 4) ; leading to equally irregular passages diminishing in size and sometimes branched as they extend towards the surface of the test (fig. 6, $c$, fig. 5, $b$, and fig. 7,e), where they appear to open in points not larger than 1-20,000th inch in diameter; at least such is the measurement of the closed dry and retracted sarcodic lining viewed in the latero-vertical section close to the surface, although the crevices among the sand-grains through which these points probably opened cannot themselves be recognized on the surface itself; floor of the chamber also more or less similarly foraminated and sulcated like the roof. Cavity of chamber often containing brown fragments of agglomerated sarcode and sponge-spicules. Size of entire specimen variable, the largest which I possess being about 1-6th inch in diameter and rather longer than broad (fig. 2). Chambers very variable in length below 1-60th inch, and equally variable in transverse diameter below the same size.

$H a b$. Marine, in excavations on the surface of a large globular mass of Siderastrcea.

Loc. ? Coral reef.

Obs. The general form of this Foraminifer is, in miniature, that of a group of sucking, half-filled leeches on the human skin, hence the name $(\beta \delta \varepsilon \lambda \lambda \alpha)$; and the composition of the test, consisting exclusively of calcareous material and fragments of siliceous sponge-spicules, seems to indicate that the coral on which the specimens were found grew on a "reef" where silex in no other shape could be obtained.

There is no doubt from this composition that it belongs to the Lituolida, or to that portion of the Arenaceous Foraminifera which hitherto have been considered "imperforate," simply because no pores on the surface could be detected by the microscope. The same might be said of the frustules of the Diatomacer even during active life, when they are in continued motion-with much more reason ; for here neither sar- 
code nor holes can be seen; but no one would be so hardy as to make this assertion; and who has ever watched a Lituola in active life?

When, however, we observe the "labyrinthic" structure of Dr. Carpenter ('Introduction to the Study of the Foraminifera,' p. 144), homologous, in my view, with the shell-tubulation of Nummulites, traversing the walls of Lituola canariensis, D'Orb. (= Nonionina Jeffreysii, Williamson, 'Recent Foraminifera of Great Britain,' 1858, p. 34, pl. iii. figs. 72 and 73) (PlateXIII. figs. 26-29), it is evident that, although large in the greater part of their course, the tubular cavities of this structure become contracted close to the surface, and that this sudden contraction, short in itself and so short a distance from the surface, thus brings the external ends of the "labyrinthic" canals immediately into view on the slightest abrasion (fig. $27, b$ ).

Admitting, then, that the shell-tubulation of Nummulites is but a counterpart of the "labyrinthic" canals, it is impossible to conceive that the ends of the latter should be brought so near the surface, if it were not intended that they should open there for the same purpose as in Nummulites. Moreover, how could the test of any kind of Foraminifera be added to externally if it were not for sarcodic filaments reaching the surface here the same as in Nummulites? Yet we learn from Dr. Carpenter ('Introd.' p. 140), that the Lituolida "can only put forth their pseudopodia from the terminal aperture," and that therefore "the affinities of the purely arenaceous types are essentially with the porcellaneows series " ('Introd.' p. 140). But who ever saw the "labyrinthic" structure (necessarily "labyrinthic" from the nature of the sandy material of which the test is composed) in the form of a porcellaneous Foraminifer, or, indeed, the shell-tubulation which is the indication to the pores on the surface? which pores, again, even here also might be so small as to escape notice without this indication; lastly, whoever saw a porcellaneous test among the Nummulites, to which Lituola canariensis in form is most nearly allied?

Here it should be remembered that the "pseudopodia" and the filaments of sarcode which pass through the surface of the test have totally different functions-the former for collecting food, and the latter chiefly for forming the shell-substance. Nowhere in Max Schultze's figures ("Ueber den Organismus der Polythalamien,' 1854), which are by far the best that were ever made, are the "pseudopodia" represented as coming from the foramina on the surface of the shell, except in fig. 22, tab. vii., where a few filaments are seen to come from the large apertures on the surface of a "young Rotalia." As a 
rule, the "pseudopodia" come from the great aperture at the end of the test in his figures-although of course, where there is a canal-system, they may issue also from its openings wherever these may be, either along the course of the septa or on the marginal cord as in Operculina.

The ferruginous colour, however, which pervades the test of Lituola canariensis is so much like that of the dried sarcode lining its cavities, while the test itself is composed of a heterogeneous assemblage of sand particles, fragments of siliceous sponge-spicules, \&c., of different sizes, varying from immeasurable minuteness to large grains which may be seen with the naked eye, that it is not extraordinary that the pores of the "labyrinthic" canals, which probably are not larger than those of the Nummulitida, viz. about 1-20,000th inch in diameter (in Operculina arabica), should, under the circumstances, not be visible among the heterogeneously composed surface of $L$. canariensis, - where there is no tubulation to lead to them, the minute passages into which they open must necessarily be crooked from the coarse arenaceous material, as before stated, through which they pass, and they can only be sought for amidst the minute particles of the cementing sand by reflected light,--when they are but just visible on the surface of Operculina, where the structure is homogeneous and translucent, there is a tubulation to lead to them, their courses respectively are straight, and they can be sought for in the centres of the tubes respectively by transmitled light.

One of these obstacles, however, is got rid of in Bdelloidina aggregata by the materials of which the test of this species is composed being almost colourless, and therefore without the ferruginous tint that exists in Lituola; hence the ultimate extent towards the surface of the dried sarcode lining the "labyrinthic" canals can, by its dark brown colour, in the vertical section be distinctly seen and measured by the microscope, so far as a "point" can be measured. But even here direct observation of the surface does not enable us to recognize the pores of the "labyrinthic" canals, because the dark point which appears to be the sarcodic lining of the pore is retracted, and there can be nothing left but the bare crevice among the minute particles of which the cementing sand is composed to indicate the opening through which it was projected-although in the vertical section, where a lateral view of the "labyrinthic" canal can be obtained, the proximity of the point is distinctly seen so near the surface that it can hardly be doubted that it once opened there (fig. 7,e).

I therefore must demur to the tests of the Iituolida being: regarded as "imperforate," and place myself on the side of 
Prof. Williamson and the late Prof. Max Schultze, in considering Lituola canariensis = Nonionina Jeffreysii, not only as being perforate on the surface, but as being only an arenaceous form of Nonionina (now with Operculina very properly included in the family Nummulitida by Dr. Carpenter). By which I mean that the Arenaceous Foraminifera should not be separated from the tests of which they are but the arenaceous forms respectively. I do not mean to state that $N$. Jeffreysii is typically the same in structure as the "vitreous" Nonionina, but that it is so as far as the heterogeneous material of which it is composed will permit. ("Hyaline or vitreous," Introd. p. 44, are bad terms for the earthy Nummulitic character, although good for the test, generally minute, which is as transparent as glass.)

Indeed it would appear impossible to view the transverse section of Valvulina (tig. 23), whose test is partly composed of vitreous and partly of arenaceous structure (fig. 24, $b, c$ )that is, the former secreted by and the latter brought to the animal (by what? Not its "pseudopodia," but by the sarcodic filaments of the surface)-without assuming that the tubulation of the vitreous (fig. $24, b$ ) is continued throughout the arenaceous layer (fig. 24, c), even if it were not distinctly visible in most species of this Foraminifer. But Dr. Carpenter, to get over this difficulty, would "assign to it [ Valvulina] an independent position as the connecting link between the two" ("Introd.' p. 146)--that is, between the "Imperforate" or Arenaceous and the Vitreous or Perforate Foraminifera. To me this "connecting link" is an indication that the "two" should never have been separated in classification.

Scratch off the outer portion of a Valvulina (fig. 24,c), and a Textularian test makes its appearance (fig. 24, b) ; that is, a Valvulina is at first a Textularia and then a Valvulina. Scratch off even the thinnest portion of the surface of Lituola canariensis, and it directly, for reasons before mentioned, presents crevices or pores like those of Valvulina both in size and shape (fig. $27, b$ ); or break open the test itself, and the intercameral holes of the septa (fig. 28, $a$ ), together with the tubulation of the walls (fig. $28, b b b$ ), are, mutatis mutandis, the same as in Nonionina among the Nummulites. That is, the homogeneous composition and definite form of the cavities in the latter are exchanged for the heterogeneous composition and consequently ill-defined form of the cavities in the former (fig. $28, a, b)$, where most of the sand-grains composing the test are from ten to twenty diameters larger than that of the tube itself in Operculina, to say nothing of the pore in its centre.

In short, where the straight tubulation ends in Valvulina 
(fig. 24, b) the labyrinthic structure commences, by the narrow pore in the centre of the tube becoming continuous, minus the tube itself, with the wide irregular cavity of the labyrinthic structure, till the latter ends in a contracted crevice on the surface (fig. 25, a). It should be remembered that the columns of the former structure are the tubes, while their cavity only is the pore (fig. $24, d$ ).

Why, if the tubulation in Valvulina is followed by the labyrinthic canals which open on the surface, should it not be so with Litwola, where the labyrinthic structure exists throughout?

Is it not, then, more consistent with nature to assume that the animal parts retain their functional arrangement and constitution although the material of the structure may be different? viz. that the septal holes remain for intercameral communication and the tubulation of the surface for the building-up of the test, whether the latter be vitreous or arenaceous, just as the chambers, doors, and fenestral openings of a house would differ if constructed of translucent homogeneous plaster, instead of enormous unhewn rocks of more or less opaque quartz. At least such is the contrast of the two under the microscope.

Still, it may be stated, "no openings on the surface can be seen in Lituola;" and this has already been granted. But are we to deny their existence simply because we cannot see them, when, as before stated, we cannot see the sarcode and the pores through which it is projected in the restless frustules of Diatomaceæ during active life? This in all probability is owing to the extreme tenuity of the one and the extreme minuteness of the other. And so it may be with the Lituolida.

In the family Nummulitida, among which, as before stated, Nonionina and Operculina are included, the pores are for the most part very minute-to wit, in the latter about 1-20,000th inch in diameter; while in Textularia they are comparatively large, being about 1-5400th inch in diameter, and in the porcellaneous tests not discemible at all.

But while they are large in Textularia, and equally so on the surface of Valvulina, where they appear in the shape of crevices between the calcareous grains of sand apparently at the expense of the minute particles of cement which bind together the large siliceous grains of the Lituolida, they may, from their smallness, easily escape notice in the latter, although they are perfectly evident in Valvulina. In short they appear to be absent even in some species of Valvulina; but it is difficult to reconcile this as fact, although they may not be visible here, when they are present in the other species. 
Thus the question is reduced to whether, under the circumstances mentioned, we are justified in concluding that the test of Lituola canariensis as well as that of Bdelloidina aggregata is imperforate because we cannot see the pores on the surface.

I think not-and therefore maintain that it is better to adopt the more probable view that they are perforate, and not "imperforate," although it may be beyond our power to demonstrate the fact in all cases-moreover that the arenaceous forms are so nearly allied to the vitreous ones respectively that they should not be separated from them in classification. In support of which I cannot do better than conclude these observations with the following statement of one whose rare amount of practical experience among both the marine and freshwater Rhizopoda, together with his acute perception, constitutes him a valuable authority.

Dr. Wallich states:--" The inference which I venture to draw from these facts is, that if due allowance be made for the well-known proneness of the Protozoa, and notably of the Foraminifera, to become modified by local or accidental conditions, the Arenaceous character, taken by itself, ought not to be regarded as indicative of new (i. e. generically distinct) "Types"; but merely of a change in the material of which the shells are composed, resulting either from a deficiency in the supply of Carbonate of Lime, or an excess of power in the water of a particular locality to hold the Carbonate of Lime in solution. And I submit that this view derives support from the undeniable fact that the Arenaceous habit is to be seen in various degrees of development in the following large series of widely divergent Genera, namely, Lagena, Bigenerina, Quinqueloculina, Textularia, Nodosaria, Uvigerina, Discorbina, and even in Globigerina itself. Whilst the "rusty" colour said to be characteristic of Lituola proper, not only pervades the entire series in varying degrees, but presents itself also (as shall hereafter be shown) amongst the Freshwater Testaceous Rhizopods." ('Deep-sea Researches: Biology of Globigerina.' By G. C. Wallich, M.D. \&c., p. 62. Van Voorst, 1876.)

I might here add that, being impressed with the idea that the testaceous freshwater Rhizopods (many of which from their rusty colour and arenaceous composition would, so far, be taken for Lituolida if found in the sea) possess the power of emitting sarcodic filaments from their surface for the purpose of forming their tests, I have occasionally seen twitching movements of the latter in the arenaceous forms, so like those witnessed in the Diatomacex that, being unable to discover the cause of this in any other way, I have set it down in both instances to the sudden separation of the free 
end of a sarcodic filament from the object to which it had, perhaps by some suctorial power, been attached.

Bdelloidina aggregata seems to approach nearest in form to Peneroplis, on account of the chambers being all on the same plane, continuous or uninterrupted by transverse partitions, linear in form and tending more or less to a spiral arrangement, with septa regularly perforated from one end to the other by holes of intercameral communication (figs. 4 and 5)-and perhaps by a disposition of the rugæ (which hang in prominent relief from the roof) to assume in some parts a transverse course, viz. across the chamber; although this would make it more like Orbiculina adunca, especially as, in some instances, there is also a tendency to a double row of holes in the septum. But from what has been above stated it will be seen that its general form is not near so like Peneroplis or Orbiculina adunca as Lituola canariensis is like Nonionina; while the uneven form and size of the sand-grains and consequent irregularity of the cavities both in Lituola canariensis and Bdelloidina aggregata are much the same, although the former is rusty and composed of quartzose sand \&.c., while the latter is colourless and composed of calcareous sand \&c. Then it should be remembered that, as all the vitreous species of a genus are not represented by arenaceous forms, so there may be some of the latter which as yet have found no vitreous representatives: perhaps Rhabdammina and Astrorhiza may belong to the latter.

Since the above was written I have mounted a piece of Bdelloidina aggregata in which both the outer and inner surfaces of the chamber are uninjured, and can see the openings of the "labyrinthic" canals on the surface, both through the latter and through the former, by transmitted light. They are extremely minute, and situated deeply in among the minuter surface-particles, where they cannot be distinguished by reflected light any more than through the internal openings of the roof, and by testing with the direction of the light can be proved to be not owing to facet-reflection of any of the arenaceous particles. So this settles the question as far as Bdelloidina is concerned; and B. aggregata being exactly like Lituola canariensis in sandy composition and structure, it may fairly be assumed that all the Arenaceous Foraminifera have pores on the surface, and therefore that the "suborder," so far as it depends on imperforation, is exploded; while thus to separate animals, merely because they happen to construct their tests of foreign particles instead of calcareous material secreted by their own bodies, or both together, would be absurd. 


\section{EXPLANATION OF PLATE XIII. (figs. 1-8).}

Fig. 1. Bdelloidina aggregata, n. gen. et sp., on a portion of Siderastraa, magnified four diameters. a, convex margin of the last chamber, along which are arranged the "pseudopodial apertures" (see fig. $5, a) ; b$, lines marking the septal limits of the chambers respectively. Diagram.

Fig. 2. The same: square indicating natural size.

Fig. 3. The same: portion of surface, magnified to show arenaceous composition of the test. Scale 1-48th inch to 1-1800th inch.

Fig. 4. The same: horizontal section of two chambers (upper half), to show:--a, septum between the two chambers; $b b$, holes of intercameral communication in the septa; $c c$, roof of chambers respectively, and internal pore-canal openings analogous to those in the shell of Nummulites. Same scale. Diagram.

Fig. 5. The same: vertical section of a chamber longitudinally, to show : $-a$, holes of intercameral communication through the septum; $b$, pore-tubulation ("labyrinthic structure") of the roof or upper wall of the chamber; $c$, basal wall or floor. Same scale. Diagram.

Fig. 6. The same: transverse section of the chamber vertically, showing:- $a$, cavity ; $b$, walls ; $c$, pore-tubulation or "labyrinthic structure." Same scale. Diagram.

Fig. 7. The same : portion of fig. 5 more magnified, to show :-a, septum; $b$, hole of intercameral communication; $c$, basal wall or floor; $d$, roof of chamber; $e$, pore-tubulation or "labyrinthic structure" amidst the sand-grains of the upper wall or roof; $f$, dark line indicative of the sarcodic layer. Diagram.

Fig. 8. The same: portion of fig. $4, c c$, more magnified, to show that the pore-canal openings are deeply sunk in the interstices of reticulated rugæ pendent from the roof. $a$, rugæ; $b$, pore-canal openings.

XVI.-On the Locality of Carpenteria balaniformis, with Description of a new Species and other Foraminifera found in and about Tubipora musica. By H. J. CarTER, F.R.S. \&c.

[Plate XIII. figs. 9-15.]

In my paper on the Polytremata (Ann. \& Mag. Nat. Hist. 1876 , vol. xvii. p. 199) the following statement is made respecting the habitat and locality of Polytrema balaniforme = Carpenteria balaniformis, viz.:-

"Hab. Marine, on the valves of Mytilicardia calyculata and other objects, viz. Pecten, Porites, \&c.

"Loc. West Indies? Indian Ocean."

"West Indies" was conjectural ; and although I have every reason for concluding that the Mytiticardia on which my specimen of $P$. balaniforme had grown had come off a sponge, it was equally conjectural where that sponge had come from originally. 